\title{
Free Flap Skin Paddle: A Painless Donor Site In Vivo
}

\author{
Anupam Golash ${ }^{1} \quad$ Raunak Shinde ${ }^{1, \oplus}$ \\ ${ }^{1}$ Department of Plastic Surgery, Calcutta Medical Research \\ Institute, Kolkata, India
}

Indian J Plast Surg 2019;52:256-257

\section{Dear Sir,}

Free flap reconstruction is an essential tool in the coverage of composite large defects for varied etiology and at varied anatomical locations. Often, in case of composite defects where the critical area of the wound is covered by the free flap, some raw area may remain at the recipient site that needs to be covered secondarily. We present an innovative way to address the issue by using the free flap skin paddle as the donor site a skin graft. Most of the times, in our clinical practice, the remnant raw area was often large enough to require a small skin graft for healing. In such cases, the skin paddle of the free flap can be used as the donor site, avoiding morbidity at a new anatomical location.

Once the flap is deemed reasonably stable (around 3-4 weeks) and the pending raw area is amenable for grafting, the skin paddle should be stabilized, gently stretched, and, with the help of skin grafting handle/dermatome, graft can be harvested from the skin paddle and applied to the raw area.

Following is a case example illustrating the use of this technique.

A middle-aged female presented with posttraumatic scalp avulsion with the skull bone exposed. The wound covered with free latissimus dorsi musculocutaneous flap with skin graft over the muscle. A residual area due to graft loss over the muscle was addressed with skin graft from the skin paddle of the free flap. The recipient raw area and the graft donor site healed well (-Figs. 1-4).

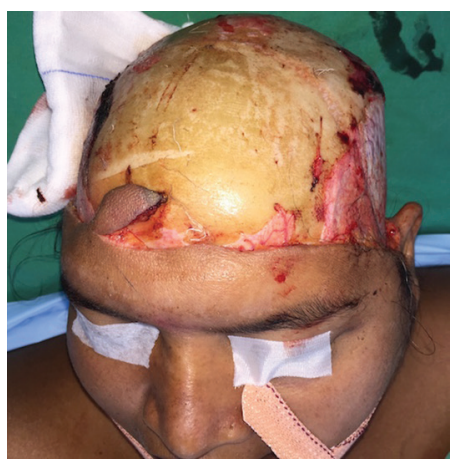

Fig. 1 Preoperative-posttraumatic scalp avulsion with exposed skull bone.
Address for correspondence Raunak Shinde, MS (Gen Surg), MCh (Plastic Surgery), Department of Plastic Surgery, HB 5, Muni Nagar, Ujjain 456010, Madhya Pradesh, India (e-mail: drraunak@hotmail.com).

There are limited reports in the literature whereby suggestions for use of skin graft from the skin paddle at the time of primary free flap harvest for closure of donor site or adjacent raw area have been made but not as a secondary donor site for the same recipient area..$^{1,2}$ The evident advantages of the technique are no additional donor-site morbidity, flap skin paddle being insensate, no need of analgesia for graft harvest, and no postoperative donor-site pain. The recipient and donor site can stay within the same dressing, and the procedure can be performed as a day-care procedure saving time and cost.

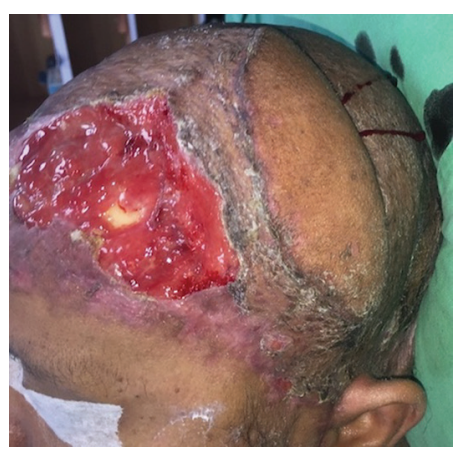

Fig. 2 Postreconstruction with free latissimus dorsi myocutaneous flap with the remnant raw area.

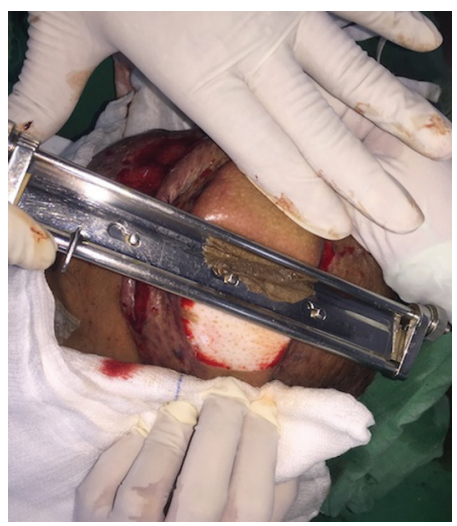

Fig. 3 Skin paddle of latissimus dorsi flap as the donor site for split-thickness skin graft.
(C)2019 Association of Plastic Surgeons of India

\section{License terms}

10.1055/s-0039-1693510

ISSN 0970-0358. 


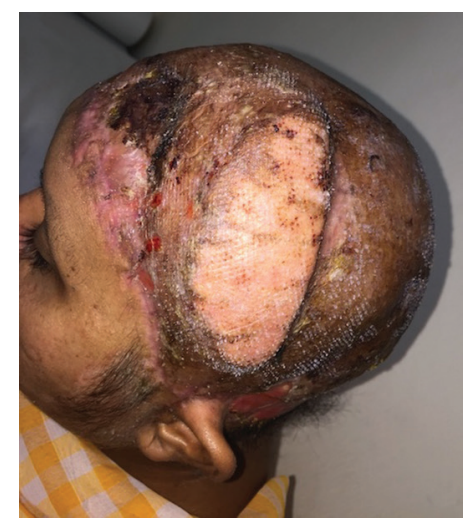

\section{Conflict of Interest}

None.

\section{References}

1 Dabernig J, Watson S. Flap skin as a donor site for split skin grafts. Ann Plast Surg 2005;55(4):439-440

2 Li AKM, Ghanem T, Use of skin grafts in free flap reconstruction. InSkin Grafts. London, UK: IntechOpen Limited; 2013

Fig. 4 Healed donor site and raw area at 2 weeks. 